\title{
Anisotropic Behaviour in Cu-Zn-Al SMA Due to the Oriented Growth of $\gamma$ Precipitates
}

\author{
A. Isalgué, F.C. Lovey*, M. Sade* and V. Torra \\ DFA, ETSECCPB/ETSAB, UPC, E-08034 Barcelona, Spain \\ * Centro Atómico Bariloche, 8400 S.C. de Bariloche, Argentina
}

\begin{abstract}
The two way shape memory effect (THSHE) is usually induced by the presence of either stabilized thin plates of martensite or particular defects breaking the symmetry of the parent phase and making only one or a few variants favourable upon transformation. Generally, the defects are created in the material by performing a certain number of transformation cycles. An alternative method to induce the TWSHE, avoiding the heavy training processes, has been obtained for Cu-Zn-Al single crystal. It consists on the introduction of small $\gamma$ precipitates by apropriated thermal treatments. Then the precipitates are made to grow asymmetrically by the action of an applied stress. Anisotropic residual stresses then favour the appearance of some selected martensite variants at the transformation cycles.
\end{abstract}

\section{INTRODUCTION}

The Two Way Shape Memory Effect (TWSME) is normally obtained by introducing defects, dislocations or arrays of dislocations in the material, by performing a certain number of transformation cycles, introducing thermomechanically an anisotropy in the beta-martensite transformation, favouring some selected variants.

However, dislocations are also created by the transformation itself, in the working cycles, producing evolution and degradation of the properties and of the two way memory effect (TWSME) during cycling. The understanding of this fact is necessary to orient the search for an improvement of the situation.

Some new methods of training have been conceived to try to overcome the main problems found in the training of TWSME. For instance, in Cu-Zn-Al alloys, the use of micro-plates of stabilised martensite has been shown to be very effective for some purposes [1]. Also, the use of geometrical constrictions to the growth of plates of martensite, together with residual stresses, has been found to be effective to obtain TWSME by means of only one ordered indentation in single crystals of $\mathrm{Cu}-\mathrm{Zn}-\mathrm{Al}$ [2]. 
The latter methods suggest that, to have a good TWSME, it would be desirable to have a 'permanent' action, in the microscopic scale for a good distribution in the material. One of the ways to accomplish this could be the presence of 'smart' particles in the material, which could help to obtain the desired anisotropy. The introduction of precipitates in the material can be a way to do this.

However, the presence of precipitates of a second phase has also considerable effects on the martensitic transformation. The interaction between the precipitates and the matrix can be a way to obtain anisotropy in the material, using the phenomena in the microstructure in a smart way to generate macroscopic phenomena.

This work reports some results about the anisotropy obtained in the martensitic transformation of $\mathrm{Cu}-\mathrm{Zn}_{\mathrm{n}} \mathrm{Al}$ by means of oriented precipitates growth.

\section{EXPERIMENTAL}

Cu-Zn-Al single crystals were used, with electronic concentration of $1.48 \mathrm{e} / \mathrm{a}$, and with nominal $\mathrm{Ms}$ of $288 \mathrm{~K}$. Small $\gamma$ precipitates were generated by cold water quenching from $773 \mathrm{~K}$, after solution treatment of $15 \mathrm{~min}$ at $1123 \mathrm{~K}$.

Mechanical tests were done in an Instron 1123 machine, equipped with furnace. This device was also used for the growing of precipitates under compressive stresses. The samples used were of cilindrical shape, with height to diameter ratio less than 3 . The single crystals were oriented by the Laue back reflection technique.

TEM was done with a Philips transmissian microscope working at 100 $k V$, for the characterisation of the precipitates. The precipitate size was in the order of $15 \mathrm{~nm}$ diameter, with uniform distribution. The mean distance among nearest precipitates was estimated to be around $150 \mathrm{~nm}$.

Dilatometric messurements were done using an Hottinger Baldwin Messtechnik (Germany) inductive LVDT as length change detector. The temperature of the sample was registered either with a Cromel-Alumel thermocouple or a Pt-100 platinum-resistance thermometer.

\section{PROPERTIES OF $\beta$ AND $m$ WITH $\gamma$ PRECIPITATES}

The presence of precipitates influences strongly the properties of SMA. The transition temperatures appear to be affected, and the behaviour of the hysteresis with the cycling process is also changed in single crystals [3], [4].

The presence of small precipitates of phases which are mechanically hard compared to the matrix produces generally a higher strength of the material, and higher yield points, as there appear to be obstasles to the dislocations movement.

In $\beta$ phase, the yield point in compression incresses strongly in the case of samples with small $\gamma$ precipitates, even though the slip system remains unchanged. At around $470 \mathrm{~K}$ the yield point increase has been found to be large: from around $150 \mathrm{MPa}$ of resalved stress in samples without precipitates (from extrapolation of data in ref. [5]), to 270 $\mathrm{MPa}$ in samples with precipitates of $15 \mathrm{~nm}$. 
However, in the martensite (m) phase, the variation of the yield point

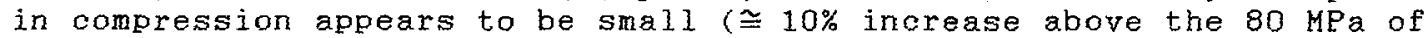
resolved stress corresponding to samples without precipitates, reported in ref. [6]). This might be due to the fact that, in m phase, the yield point corresponds to stresses near the variant to variant reconversion process. Then, even if the precipitates impede the dislocation rearrangement giving rise to glide and yielding for one martensite variant, yielding might occur as a result of local variant reconversion, and further dislocation generation at the interfaces.

The presence of hard precipitates of a second phase has important effects on the martensitic transformation. Changes in the transformation temperatures, wider hysteresis and evolution of the hysteresis width with cycling have been observed in $\mathrm{Cu}-\mathrm{Zn}-\mathrm{Al}$ alloy with $\gamma$ precipitates. The evolution of the hysteresis width has been interpreted in terms of dislocation loop creation around the precipitates, giving account for the decreasing of the relatively large hysteresis in the first cycles. The mortensite plastic acoomodation around the precipitates in the martensitio transformation, explains the asymtotic hysteresis width, which is higher than on air-quenched samples [4].

\section{ASSTMETRIC GROWTH OF $\gamma$ PRECIPITATES AND INDUCED TRANSFORMATION ANI SOTROPY}

Precipitate growth can be influenced by external applied stresses. From the minimization of surface precipitate energy plus elastic terms, it has been shown that there might exist a precipitate shape transition, depending on stress and precipitate size on a given system [7].

Flash heating at temperatures between $520 \mathrm{~K}$ and $770 \mathrm{~K}$ has been shown to be effective for $\gamma$ phase precipitate growth [3]. We have used lower temperatures, around $460-490 \mathrm{~K}$ in order to have time to perform reliable mechanical tests at a given temperature. The ageing time needed to double our precipitates mean diameter at $475 \mathrm{~K}$ was found to be around $1 \mathrm{~h}[8]$.

From the yield point in samples with precipitates, we evaluated the stresses that can be applied to the samples in the precipitates growing process. The compressive axis of our samples enabled to use maximum normal stresses of near $600 \mathrm{MPa}$. Oriented assymetric precipitate growth could be observed at these stresses, after aging at these temperatures for enough time. Fig. 1 shows the different appearance of the precipitates along equivalent cubic directions, which implies the non-symmetry of the $\gamma$ phase precipitates.

The assymmetry induced by the oriented growth of the precipitates under stress may be used to break the (crystallographic) symetry of thermal martensite plates nucleation and growth; however, the growth of the precipitates has to be controlled in order to avoid an excessive change of the transformation temperatures, which decrease strongly with increasing precipitate size. With this restriction, TWSME has been obtained in samples with $\gamma$ precipitates grown under compressive stress. Fig. 2 shows the lengthening-temperature hysteresis cycle of a $\mathrm{Cu}-\mathrm{Zn}-\mathrm{Al}$ sample of $3.1 \mathrm{~mm}$ length, with $\gamma$ precipitates grown for 10 min at $460 \mathrm{~K}$ under $510 \mathrm{MPa}$ of compressive stress. The relative increase of the precipitates mean diameter in the growing process is of the order of $10 \%$. Fig. 3 shows the appearance of the $\gamma$ precipitates after growth, in dark field TEM image obtained with a $\gamma$ precipitates spot. 


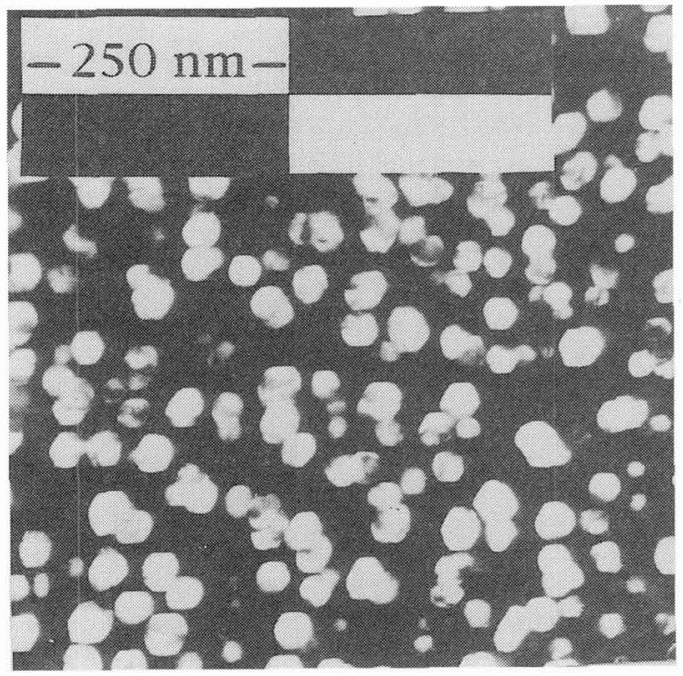

a

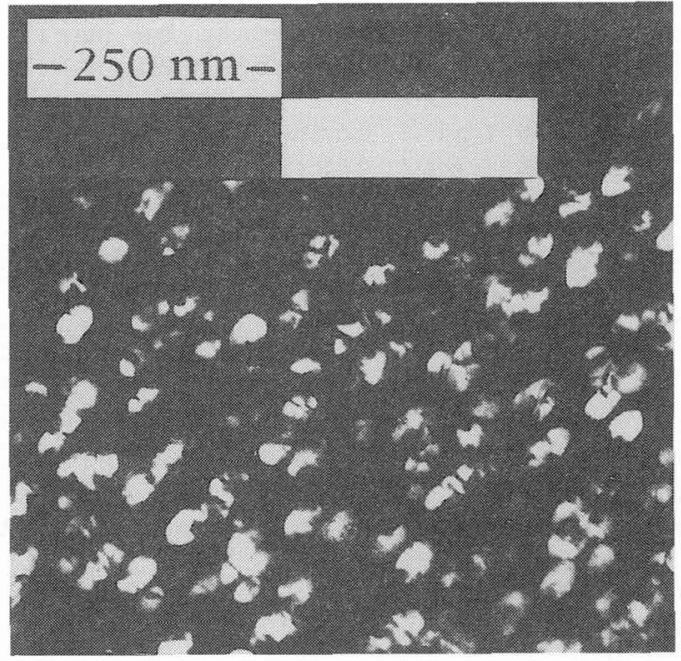

b

Figure 1.- Dark field TEM images of precipitates grown under 590 MPa of compressive normal stress, and $50 \mathrm{~min}$. at $483 \mathrm{~K}$ : a) projected precipitate image at 30 degrees of compressive axis; and b) at 105 degrees of compressive axis.

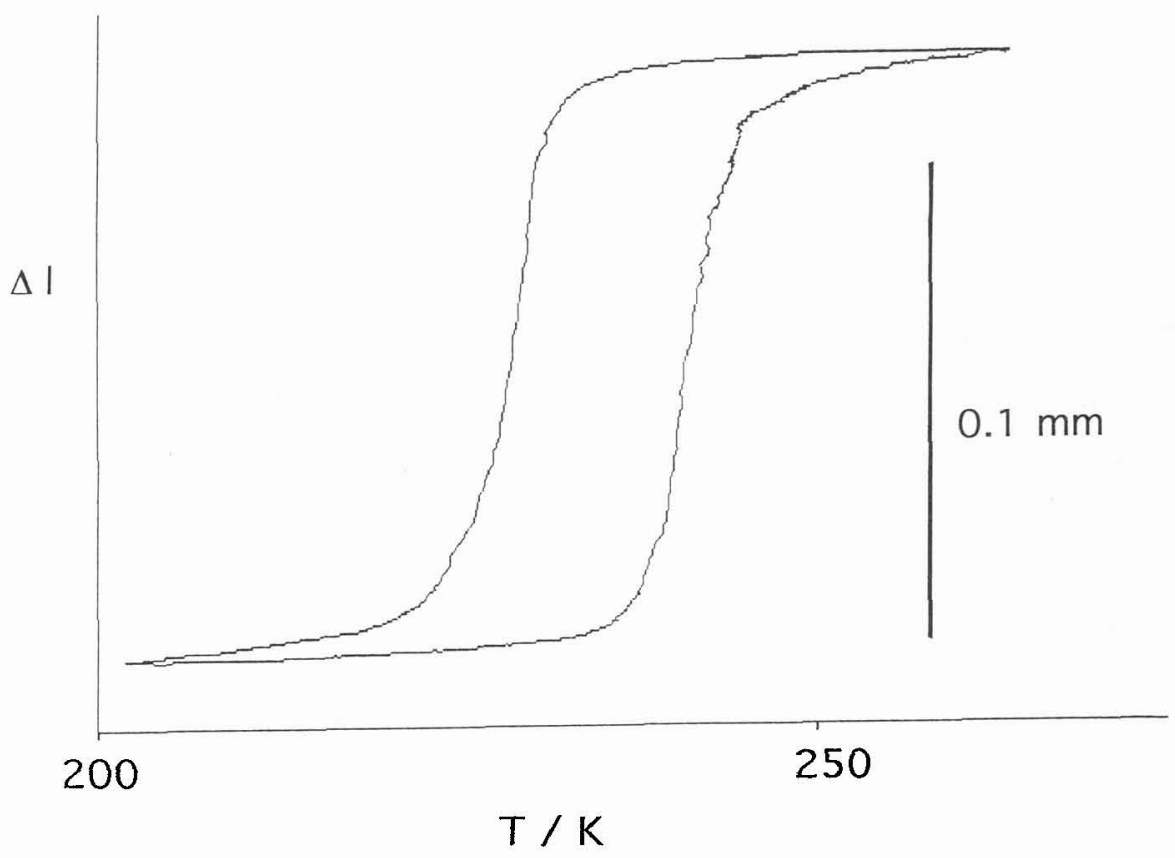

Fig. 2. Change of lenght in a thermal induced martensitic transformation in a Cu-2n-Al single crystal sample with $\gamma$ precipitates grown under stress (as explained in the text). 


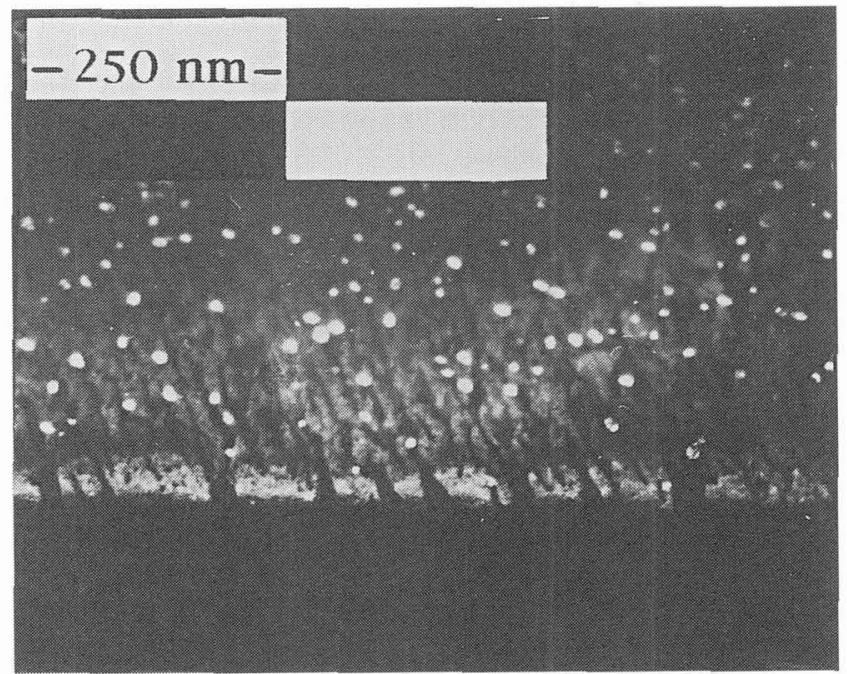

Fig. 3. $\gamma$ precipitates after growth under compressive stress, in the sample with TWSKE.

\section{DISCUSSION}

The spontaneous change in length in the thermal transfarmation of Fig. 2 is a TWSME, obtained without any previous beta- martensite-beta eycle.

The first beta to martensite transformation shows an anisotropic behaviour induced by the energetic preference of some martensite variant due to the residual stresses which build up as a result of the assymetric precipitate shape. Further transformations proceed in the same way either because the residual stresses remain in the sample, or because the appearance of martensite generates loops of dislocations around the precipitates which are compatible with the martensite variant favoured in the process. These loops favour the plastic deformation of martensite around the precipitates, to accommodate the shape change of the matrix in the transformation [4].

In both cases the result of TWSME would be obtained. However, as in

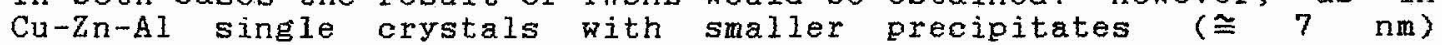
dislocation loops around the precipitates have been abserved after martensitic transformation [4], it appears more likely that in our samples the first cycles are essentially driven by residual stresses. The preference for some martensite variants that produces further cycles giving TWSME is driven by the energy differences associated to the presence of the dislocation loops around the precipitates. This process can be considered as a kind of 'self-training'.

On the other hand, it should be also noted that the important point in the training of samples with precipitates is the presence of relatively hard, permanent nuclei in the material, which offer an easier permanence of induced anisotropies in the training process [9]. 
The increase of the yielding point associated to the presence of precipitates gives an indieation of the inereased dificulties to dislocation movement, which imply a stronger permanence of the "classical" training associated to dislocation arrangements.

\section{CONCLUSIONS}

TWSME has been obtained in single crystals of Cu-Zn-Al, using the properties of material with precipitates, by means of assymmetric precipitate growth under stress. Thus, the symmetry of the material is broken, giving rise to a preference for some martensite variants in the thermally induced transformation. Further transformations proceed in the same way because the first transformation paths induce the appearance of dislocation loops axound the precipitates, favouring the same martensite variants upon mechanical accommodation of the relatively hard precipitates by martensite plastic deformation.

The presence of hard, permanent nucleus, as the $r$ precipitates are in the used alloy, is the determinant fact for the appearance of a relevant, effective TWSME.

\section{ACKNOWLEDGEMENTS}

Grants from EEC, CI1*-CT91-0943 (HSMM), from DGICYT 92-113, and from CICYT PTR93-0049 and MAT82-1025-C02-01 are gratefully acknowledged.

\section{REFERENCES}

[1] R. Rapacioli, V. Torra, E. Cesari, J.M. Guilemany, J.R. Miguel: Scripta Metal1, 22 (1988) 261-264

[2] MR. Dalmau, A. Isalgué, F. Marco, V. Torra: Spanish patent no. 9002101.

[3] F.C. Lovey, E. Cesari: Mater. Sci. Eng. 129A, 127-33 (1990).

[4] FC. Lovey, V. Torra, A. Isalgué, D. Roqueta, M. Sade: Acta Metall. Mater. $42,453-60(1994)$.

[5] R. Romero, M. Ahlers, F.C. Lovey: Phil. Mag. 58A, 881-903 (1988).

[6] A. Cuniberti, R. Romero, M. Ahlers: Scripta Metall. Mater. 26, 495 (1992).

[7] W.C. Johnson, M.B. Berkenpass, D.E. Laughlin: Acta metall. 36 (12), 3149-62 (1988)

[8] A. Isalgué, F.C. Lovey, M. Sade: Scripta Metall. Mater. 28, $1183-88$ (1993).

[9] J. Fernández, J.M. Guilemany, A. Isalgué, F.C. Lovey, V. Torra: Spanish patent no. 9400988 . 